\title{
Laparoscopic hepatectomy in a morbidly obese patient with liver cirrhosis: A case report
}

\author{
NIKOLAOS MACHAIRAS, IOANNIS D. KOSTAKIS, DIMITRIOS MANTAS and GEORGIOS C. SOTIROPOULOS
}

\author{
2nd Department of Propedeutic Surgery, University of Athens Medical School, \\ General Hospital Laiko, 11527 Athens, Greece
}

Received August 29,2016; Accepted November 21, 2016

DOI: $10.3892 / \mathrm{mco} .2016 .1109$

\begin{abstract}
Cirrhotic patients constitute a high-risk population, and present a major challenge for the performance of minimally invasive laparoscopic resections due to difficulties in parenchymal transection. The present study describes the case of a 71-year-old morbidly obese male patient who was referred to our department with a hepatic mass identified on routine abdominal ultrasound. Abdominal computer tomography and magnetic resonance imaging confirmed a mass in segments V-VI of the liver, highly suspicious for HCC. The patient's past medical history additionally included non-alcoholic steatohepatitis, diabetes mellitus and arterial hypertension and myocardial infarction. The patient's body mass index was $45 \mathrm{~kg} / \mathrm{m}^{2}$, and the American Society of Anesthesiologists' classification of preoperative risk was 3 . The patient underwent laparoscopic resection of segments V-VI and cholecystectomy. Two years postoperatively, the patient remains disease-free and in excellent condition. To the best of our knowledge, this is the first report on laparoscopic liver resection for such a morbidly obese patient in the context of advanced liver cirrhosis.
\end{abstract}

\section{Introduction}

Progress in laparoscopic techniques and expertise, in combination with technological advances, have led to a more widespread performance of laparoscopic hepatic resections for hepatocellular carcinoma (HCC) over the last 15 years. It is accepted that laparoscopic liver resection (LLRs) is a safe procedure, with acceptable morbidity and mortality for both minor and major liver resections (LRs) (1). Cirrhotic

Correspondence to: Dr Georgios C. Sotiropoulos, 2nd Department of Propedeutic Surgery, University of Athens Medical School, General Hospital Laiko, Agiou Thoma Street 17, 11527 Athens, Greece

E-mail: geosotirop@med.uoa.gr

Key words: liver cirrhosis, morbid obesity, liver resection, minimal invasive surgery, laparoscopy patients constitute a high-risk population, and present a major challenge for the performance of minimally invasive LR due to difficulties in parenchymal transection. Several studies have reported successful application of laparoscopic hepatic resections in selected cirrhotic patients, despite the presence of greater preoperative comorbidities $(2,3)$. In the present study, the case of a morbidly obese, cirrhotic patient who was admitted to the General Hospital Laiko for an HCC, and who successfully underwent a laparoscopic segmental hepatic resection, is reported.

\section{Case report}

A 71 year-old morbidly obese male patient with cirrhosis due to hepatitis B virus (HBV) infection and alcoholic hepatitis was referred to our department at the General Hospital Laiko with a hepatic mass identified on performing abdominal ultrasound. The patient, who was routinely evaluated for chronic HBV infection, was asymptomatic. Abdominal computer tomography and magnetic resonance imaging confirmed a mass in segments V-VI of the liver $(4.7 \times 4.5 \times 4.3 \mathrm{~cm})$, highly suspicious for HCC (Fig. 1). The patient's past medical history additionally included non-alcoholic steatohepatitis (NASH), diabetes mellitus, arterial hypertension and myocardial infarction. The patient's body mass index (BMI) was $45 \mathrm{~kg} / \mathrm{m}^{2}$, the American Society of Anesthesiologists' classification of preoperative risk was 3, and the liver function was classified as Child-Pugh class A $(4,5)$. The patient's $\alpha$-fetoprotein level was $5.5 \mathrm{ng} / \mathrm{ml}$. He underwent laparoscopic resection of segments V-VI and cholecystectomy. The operative time was $105 \mathrm{~min}$. During the early postoperative period, the patient developed a moderate renal and hepatic failure that regressed gradually over the course of the following next days, not necessitating any intervention, and was classified as grade II according to the Dindo-Clavien classification (6). The patient was discharged on the eighth postoperative day. Histology and immunohistochemistry [cytokeratin (CK) 7, CK19, epithelial membrane antigen (EMA), $\alpha$-fetoprotein (AFP), CEApol, glypican-3, CD10] revealed a moderately differentiated HCC, with negative resection margins (R0 resection), without vascular or lymphatic invasion [stage pT1, according to the tumor-lymph nodes-metastasis (TNM) staging system]. Two years postoperatively, the patient remains disease-free and in excellent condition. 


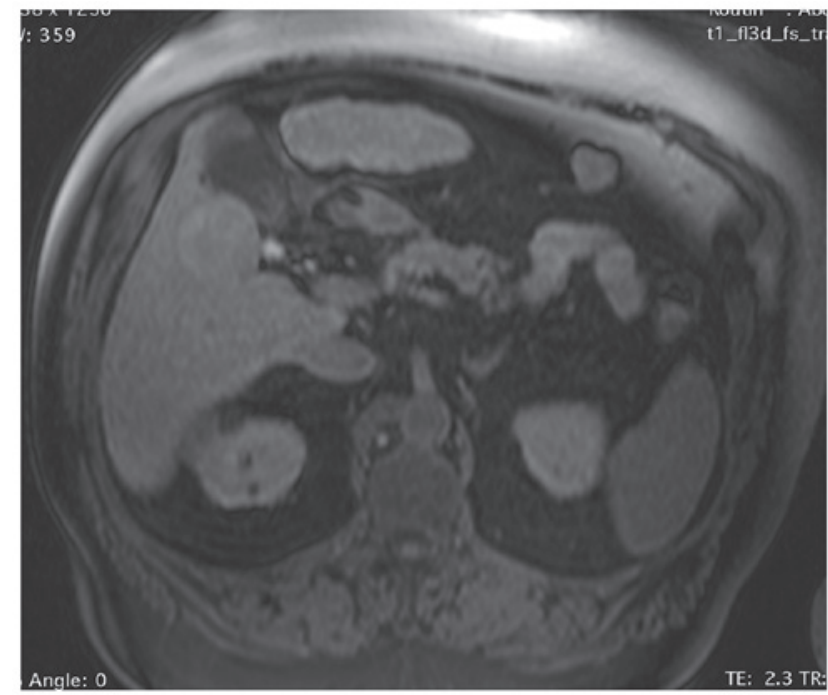

Figure 1. Magnetic resonance imaging of the liver lesion.

\section{Discussion}

Morbid obesity has a continually increasing prevalence worldwide, and has been associated with worse postoperative outcomes due to correlated co-morbidities, as well as technical intraoperative difficulties. In the context of liver disease, obesity is associated with various liver diseases, including fatty liver disease and NASH. From the limited data available, recent studies have shown that hepatic resections in obese patients may be safely performed with no additional risk compared with non-obese patients (7). Laparoscopic liver surgery in this population presents a surgical challenge, and yet, since the BMI has not been reported to negatively affect the postoperative short-term outcomes in patients undergoing LLR, the laparoscopic approach is not considered to be a

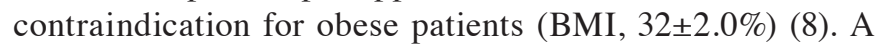
study by Toriguchi et al (9) underlined the benefits of LLR in obese patients, with a median BMI of $26.8 \%$ (range 25-38.2\%), reporting significantly lower intraoperative blood loss and hospital stays compared with obese patients operated on with open liver resection (9). A more recent study exploring the impact of BMI on surgical outcomes in patients undergoing LLR (median BMI, 24.1 $\pm 4.1 \%$ ) compared with open LR (median $\mathrm{BMI}=23.1 \pm 3.9 \%$ ) demonstrates that LLR in obese patients may be performed as safely as in non-obese patients, with the same risk of postoperative complications and with, additionally, lower operation times and levels of blood loss compared with non-obese patients (10). Furthermore, the study by Uchida et al (10) also reported a marked correlation of the BMI with operation time and blood loss in open LR; however, no such correlation is demonstrated in LLR. It should be noted that the results of these studies coming from Asian patient populations $(9,10)$ are to be interpreted with caution, since patients are considered obese with a BMI of $25 \mathrm{~kg} / \mathrm{m}^{2}$, or even $24 \mathrm{~kg} / \mathrm{m}^{2}$, contrary to the World Health Organization (WHO) standard of BMI of $30 \mathrm{~kg} / \mathrm{m}^{2}(11,12)$. Such a phenomenon constitutes an additional strength of our report, since there are actually only limited published data on LLR for a morbidly obese patient, in our case with a BMI of $45 \mathrm{~kg} / \mathrm{m}^{2}$.

In conclusion, to the best of our knowledge, this is the first case report on laparoscopic liver resection for such a morbidly obese patient in the context of advanced liver cirrhosis.

\section{References}

1. Nguyen KT, Gamblin TC and Geller DA: World review of laparoscopic liver resection-2,804 patients. Ann Surg 250: 831-841, 2009.

2. Twaij A, Pucher PH, Sodergren MH, Gall T, Darzi A and Jiao LR: Laparoscopic vs open approach to resection of hepatocellular carcinoma in patients with known cirrhosis: Systematic review and meta-analysis. World J Gastroenterol 20: 8274-8281, 2014.

3. Cheung TT, Dai WC, Tsang SH, Chan AC, Chok KS, Chan SC and Lo CM: Pure laparoscopic hepatectomy versus open hepatectomy for hepatocellular carcinoma in 110 patients with liver cirrhosis: A propensity analysis at a single center. Ann Surg 264: 612-620, 2016.

4. ASA Physical Classification System 2016. hhtp://www.asahq.org Accessed June 2016

5. Pugh RN, Murray-Lyon IM, Dawson JL, Pietroni MC and Williams R: Transection of the oesophagus for bleeding oesophageal varices. Br J Surg 60: 646-649, 1973.

6. Dindo D, Demartines N and Clavien PA: Classification of surgical complications: A new proposal with evaluation in a cohort of 6336 patients and results of a survey. Ann Surg 240: 205-213, 2004.

7. Utsunomiya T, Okamoto M, Kameyama T, Matsuyama A, Yamamoto M, Fujiwara M, Mori M, Aimitsu S and Ishida T: Impact of obesity on the surgical outcome following repeat hepatic resection in Japanese patients with recurrent hepatocellular carcinoma. World J Gastroenterol 14: 1553-1558, 2008.

8. Nomi T, Fuks D, Ferraz JM, Kawaguchi Y, Nakajima Y and Gayet B: Influence of body mass index on postoperative outcomes after laparoscopic liver resection. Surg Endosc 29: 3647-3654, 2015.

9. Toriguchi K, Hatano E, Sakurai T, Seo S, Taura K and Uemoto S: Laparoscopic liver resection in obese patients. World J Surg 39: 1210-1215, 2015.

10. Uchida H, Iwashita Y, Saga K, Takayama H, Watanabe K, Endo Y, Yada K, Ohta M and Inomata M: Benefit of laparoscopic liver resection in high body mass index patients. World $\mathrm{J}$ Gastroenterol 22: 3015-3022, 2016.

11. Kanazawa M, Yoshiike N, Osaka T, Numba Y, Zimmet P and Inoue S: Criteria and classification of obesity in Japan and Asia-Oceania. World Rev Nutr Diet 94: 1-12, 2005.

12. Obesity: Preventing and managing the global epidemic. Report of a WHO Consultation. World Health Organ Tech Rep Ser 894: i-xii, 1-253, 2000. 